Trabajos y Comunicaciones, 2da. Época, N 46, e047, octubre 2017. ISSN 2346-8971

Universidad Nacional de La Plata.

Facultad de Humanidades y Ciencias de la Educación.

Departamento de Historia

\title{
La persistencia de lo nacional-popular (a propósito de historia y política en René Zavaleta Mercado)
}

\author{
The Persistence of the National-Popular (On History and Politics in \\ René Zavaleta Mercado)
}

\section{Marcelo Starcenbaum *}

* Instituto de Investigaciones en Humanidades y Ciencias Sociales / Universidad Nacional de La Plata-CONICET, Argentina | mstarcenbaum@gmail.com

PALABRAS CLAVE

René Zavaleta Mercado

Nacional-popular

Historia

Política

\section{RESUMEN}

El objetivo de este trabajo es analizar los modos específicos de articulación entre historia y política en la obra de Zavaleta Mercado y aproximarse a los modos diferenciados en los cuales en dicho trabajo es captada la experiencia de la Revolución Nacional. A través de una lectura de sus trabajos más significativos, constatamos que el problema de lo nacionalpopular constituye un elemento de permanencia a lo largo de toda su obra. Veremos que, más allá de las diferentes etapas que atraviesa su trabajo, la experiencia de la Revolución Nacional es objeto de una perspectiva analítica en la que la interpretación de la política está asociada a una fuerte noción de historicidad.

\section{KEYWORDS}

René Zavaleta Mercado

National- popular

History

Politics

\section{ABSTRACT}

The objective of this work is to analyze the specific ways of articulating history and politics in the work of Zavaleta Mercado and to approach the differentiated modes in which the experience of the National Revolution is understood in this work. Through a reading of his most significant works, we find that the problem of the national-popular is an element of permanence throughout his work. We will see that, beyond the different stages of his work, the experience of the National Revolution is the subject of an analytical perspective in which the interpretation of politics is associated with a strong notion of historicity. 
I.

En un texto poco visitado sobre la figura de René Zavaleta Mercado, Hugo Zemelman (1985) se refería a él como un caso representativo del intelectual que enmarca sus análisis en el interior de un compromiso político. De esta manera, el sociólogo chileno insistía en que los esfuerzos de Zavaleta Mercado por comprender la realidad de Bolivia habían estado siempre atados a un proyecto de desarrollo de la nación boliviana. Al priorizar la historicidad de sus afirmaciones por sobre las teorizaciones, los análisis de Zavaleta Mercado habrían constituido “intentos por captar una realidad en su compleja concreción histórica para poder definir, a partir de ella, las opciones de desarrollo que se contienen en un momento de la historia” (Zemelman, 1985: 562). Desde otro espacio de enunciación, Mauricio Souza Crespo (2011) ha sugerido que la obra de Zavaleta Mercado puede ser leída en clave de una fidelidad política e intelectual a la Revolución de 1952. A modo de guía de lectura de la reciente reedición de su obra, este comentarista aludía al acontecimiento revolucionario como el principal elemento de recurrencia en la totalidad de la producción zavaletiana. La Revolución Nacional tendría una presencia tal en la reflexión de Zavaleta Mercado que su obra podría ser considerada básicamente como "una biografía del 52” (Souza Crespo, 2011: 12).

En este trabajo realizamos una lectura de la obra de Zavaleta Mercado que pretende conectar las sugerencias recientemente mencionadas. Es decir, por un lado nos interesa indagar en los modos en los que se vinculan política e historia en su obra. De esta manera, realizaremos un repaso de sus textos más significativos a los fines de evidenciar que el lugar que ocupa la política en sus reflexiones está estructuralmente atravesado por una comprensión histórica de la realidad social. Por otra parte, estamos interesados en mostrar que esta forma de conjugación entre política e historia está íntimamente conectada con el lugar que ocupa en sus reflexiones la experiencia de la Revolución Nacional. Al respecto, la revisión de sus escritos nos permitirá advertir que a lo largo de toda su trayectoria intelectual la aproximación a la secuencia revolucionaria en términos de una política singular estará mediada por una fuerte noción de historicidad. En este sentido creemos que en el tratamiento otorgado por Zavaleta Mercado al problema de lo nacional-popular se cristaliza el anudamiento del vínculo entre historia y política con la fidelidad a la Revolución de 1952. Por un lado, porque el abordaje del acontecimiento revolucionario y el orden societal que éste configura está mediado por un esquema en el que se articulan de manera afirmativa gobiernos nacionales, políticas estatales y mayorías populares. Por el otro, porque la aproximación a la experiencia política del MNR está indisolublemente ligada a una concepción histórica de la formación social boliviana en la que tienen un rol relevante las condiciones sobre las cuales dicha experiencia se despliega.

El interés concitado por la obra de Zavaleta Mercado en los últimos años ha generado el singular efecto de restituir las periodizaciones clásicas sobre su trayectoria a la vez que matizarlas en nombre de aproximaciones específicas. Como es ampliamente conocido, el trabajo de Luis Antezana (1991) ha establecido la periodización canónica de la obra de Zavaleta Mercado en un momento nacionalista, que abarcaría desde mediados de la década de 1950 hasta mediados de la de 1960, uno marxista ortodoxo, que comprendería la década de 1970, y uno marxista heterodoxo, que abarcaría la primera mitad de la década de 1980. En un diálogo productivo con la lectura de Antezana, algunos estudios recientes han complejizado la división de los escritos zavaletianos en un período nacionalista y en uno marxista pasible de ser dividido a su vez en dos momentos. Por ejemplo, al enfatizar la presencia que tiene el problema de la nación en su obra, Diego Giller (2016) ha matizado la oposición entre nacionalismo y marxismo postulando la continuidad de una reflexión en torno a las relaciones entre teoría local y teoría universal. Asimismo, Mauricio Gil (2006) ha propuesto una reinterpretación de la mencionada polarización al evaluar la obra de Zavaleta Mercado desde una perspectiva más filosófica que política. En este dossier, Luciana Cadahia sugiere algo similar desde una lectura filosófica del problema de la paradoja señorial en Lo nacionalpopular en Bolivia. Por nuestra parte, la hipótesis de una persistencia de lo nacional-popular implica una lectura de la obra de Zavaleta Mercado más atenta a las torsiones que a las discontinuidades. Si bien atendemos los marcos nacionalistas y marxistas de sus análisis, nos interesa especialmente indagar en la constancia de una reflexión acerca de lo nacional-popular. En este sentido, veremos que si bien dotado de diferentes coloraciones según el predominio del esquema nacionalista o el marxista, el abordaje de la experiencia de la Revolución 
Nacional desde una mirada que articula política e historia constituye un elemento de permanencia a lo largo de su obra.

\section{II.}

Los modos de conjugación entre historia y política en los textos tempranos de Zavaleta Mercado encontraban sustento en la tradición del nacionalismo revolucionario boliviano. En este sentido, un repaso por la obra paradigmática de aquella corriente, Nacionalismo y coloniaje de Carlos Montenegro, habilita la reposición del sustrato intelectual sobre el que se desplegarán las intervenciones de Zavaleta Mercado en las décadas de 1950 y 1960. Escrito en 1943, este libro se proponía como tarea fundamental "restablecer la verdad del devenir boliviano, desconocida o falsificada por el pensar y el sentir antibolivianista con que se concibe y se escribe una grande porción de la historia patria” (Montenegro, 1944: 37). En tanto expresión de la condición colonial, este sentimiento antinacional se prolongaba en un relato histórico que exaltaba lo foráneo a la vez que negaba sistemáticamente lo nativo. En lugar de focalizarse en el protagonista natural de la experiencia local, es decir, el boliviano, este relato postulaba al extranjero como el sujeto y objeto exclusivo de la historia nacional. Se trataba según Montenegro de una inversión que conllevaba tanto una destrucción de las creencias colectivas como la eliminación de toda noción histórica en el seno del pueblo. Frente a las operaciones legitimadoras de la dependencia, la restauración de la historia patriótica impulsada por el nacionalismo revolucionario implicaba la suplantación de la narrativa oligárquica a través de una concepción de lo nacional como “energía histórica afirmativa y, por lo mismo, creadora y perpetuadora” (Montenegro, 1944: 41). 1

La necesidad de dotar a lo nacional de una energía histórica afirmativa permite comprender los términos en los cuales Zavaleta Mercado procesó en la década de 1950 las políticas desplegadas por la izquierda boliviana en los marcos de la Revolución Nacional. En este sentido su libro El asalto porista nos permite advertir cuáles eran las dimensiones de la politicidad del trotskismo boliviano que se volvían problemáticas desde un esquema interpretativo nacionalista revolucionario. $\underline{2}$ Una de ellas era la imagen distorsionada del lugar ocupado por Bolivia y América Latina en el sistema imperialista mundial. Si bien las interpretaciones trotskistas se desenvolvían en un terreno diferenciado de aquella narrativa oligárquica apuntada por Montenegro, se desentendían de la misma manera de los problemas relativos al devenir nacional. Era este desinterés el que propiciaba una contradicción flagrante entre las instigaciones políticas del trotskismo y sus esfuerzos por dar cuenta de la naturaleza de la experiencia emenerrista. Por una parte, el POR le reclamaba al MNR mayor radicalidad frente al problema de la dominación imperialista sobre el territorio boliviano. Por el otro, intentaba demostrar la ineficacia del imperialismo con el fin de evidenciar la tolerancia desarrollada por Estados Unidos frente a políticas de liberación nacional como la protagonizada por el MNR. En un contexto histórico marcado por el derrocamiento de Jacobo Arbenz y el avizoramiento del asedio estadounidense a la Revolución Cubana, la lectura trotskista no podía ser sino desmentida. En palabras del boliviano:

"La experiencia de Guatemala, el malletazo de los infames, y la que a veces parece cerñirse inminente sobre Cuba, enseña que la Revolución es algo que hay que hacer en la economía silenciosa y áspera antes que en las conferencias de prensa. En este sentido, las bullas falsas, trotskistas como stalinistas, parecen más bien complementarias del imperialismo que sus adversarias” (Zavaleta Mercado, 1959: 4)

Más que regresar a la cuestión de la complicidad entre los planteos izquierdistas y la dominación imperial, tópico recurrente del discurso nacionalista revolucionario, nos interesa profundizar en las implicaciones que tenía el ataque al trotskismo para un planteo acerca de las particularidades de una práctica política comprometida en un proyecto nacional-popular. En este sentido, la contraposición entre “conferencias de prensa” y una "economía silenciosa y áspera” remite a una conceptualización de la política como intervención que se despliega necesariamente en coyunturas atravesadas por relaciones de fuerza. La práctica política conlleva una economía del silencio porque, alejada de las aclamaciones, se despliega a través de alianzas estratégicas y construcciones que 
implican avances y retrocesos. Asimismo supone una economía de la aspereza porque, lejos de los purismos, el establecimiento de las alianzas y el tránsito por los momentos de repliegue están acompañados por acuerdos y concesiones. Como puede advertirse, lo que diferenciaba las formulaciones de Zavaleta Mercado de las del trotskismo era una concepción de la política fuertemente ligada a una noción de historicidad. Contrapunto que se evidencia de manera contundente en la manera divergente en la que ambos concebían la adhesión política de los obreros mineros a la Revolución Nacional. Al considerar que los obreros bolivianos estaban “en tránsito” por el MNR, el trotskismo podía establecer un programa político en el que cabían tanto el control ideológico en el ámbito sindical como el eventual derrocamiento del gobierno de la Revolución Nacional. Al depositar el locus de la política en un ideal externo a la historia, la dirigencia trotskista quedaba habilitada para desconocer las transformaciones históricas operadas entre el régimen oligárquico y la experiencia nacional-popular. Abstracción de tal tenor que conducía al pensador boliviano a caracterizar a dicha dirigencia como "una fauna fanática que sólo se mueve con comodidad en medio de un misticismo helado e implacable” (Zavaleta Mercado, 1959: 10).

Los términos de semejante calificación se vuelven inteligibles si profundizamos en las concepciones de la nación que operan en la producción zavaletiana de la época. Dichos sentidos pueden ser rastreados en La formación de la conciencia nacional, texto paradigmático de su período nacionalista revolucionario y que puede ser captado como una actualización de los postulados de Montenegro al momento histórico inaugurado por la Revolución Nacional. En él, Zavaleta Mercado comparte con el nacionalismo revolucionario de la década de 1940 la hipótesis de la confabulación antiboliviana. En tanto país semicolonial, Bolivia era objeto de la acechanza de los intereses extranjeros y la enajenación de sus propias clases dominantes. Como afirma Tapia (2002: 60), Zavaleta Mercado forma parte de una discursividad basada en una ontología histórica polar que tiene como extremos condensadores a la nación y la antinación. En ella, la nación es dotada de un carácter fáctico. Es decir, constituye un elemento resistente y perseverante en los marcos de una condición histórica que conspira contra ella de manera permanente. Más allá de la penetración extranjera, la explotación económica y la dependencia cultural, la nación sobrevive como “un factum disperso, consistente e inédito en las clases nacionales” (Zavaleta Mercado, 1967: 65). Tal como puede advertirse, la concepción de la nación como factum está asociada estrechamente a la valoración de determinadas clases sociales como instancias que albergan a la nacionalidad aún en los momentos más hostiles para su despliegue afirmativo. Como afirmara al respecto en uno de sus pasajes más iluminadores, "la nación inevitable y carnal, hecho a veces pasivo pero presente siempre y existente sin dudas, sobrevive así a pesar de un interminable acecho, de las catástrofes, de las mutilaciones territoriales, de la instalación pertinaz de la pedagogía oligárquica” (Zavaleta Mercado, 1967: 66).

A diferencia de la interpretación fundacional de Montenegro, la lectura zavaletiana de la década de 1960 abordaba el problema de la nación teniendo como referencia histórica el desarrollo de una experiencia nacional y revolucionaria. En este sentido la Revolución Nacional opera en Zavaleta Mercado como el elemento divisorio de dos momentos históricos en los que se conjugan de manera diferenciada nación y clases sociales. En el primero de ellos, como dijimos, la nación sobrevive en ese estado complejo en el que se anudan pasividad y perseverancia. En este momento, los obreros y los campesinos están imposibilitados de expresar una pretensión coherente de poder, por lo que su rol queda reducido a la resistencia y la conservación. El sometimiento y la enajenación impiden que la politicidad de las clases nacionales avance más allá de las lógicas de la irrupción y el desorden. Se produce por tanto una especie de suspensión de lo nacional, ya que mientras las clases nacionales no pueden afirmar la nación, la oligarquía se mantiene absolutamente ajena a todo lo relacionado con ella. Insertos en las tramas económicas, políticas y culturales del imperialismo, los latifundistas y el gran capital minero desarrollan un vínculo con el medio local que necesariamente tiende a perpetuar la colocación de Bolivia como país semicolonial. Era precisamente la escisión entre oligarquía y nación la que bloqueaba la posibilidad de que fueran puestos en cuestión los pilares que estructuraban la formación social boliviana. En el plano económico, el despojo de los recursos naturales. En el social, la explotación de la población indígena. En el de la política, “la rosca”, una estructura semiestatal impregnada de burocracia, corrupción y prebendas. $\underline{3}$

En el recorrido propuesto por Zavaleta Mercado, la propia lógica del imperialismo crea en el momento 
antinacional las condiciones para que los obreros y los campesinos trasciendan su politicidad defensiva. Esto ocurre, por ejemplo, con la Guerra del Chaco, en la que las clases nacionales deben ser necesariamente movilizadas por la oligarquía. ${ }^{4}$ A modo de efecto no deseado de dicha movilización, las clases nacionales perciben que son irremplazables para la defensa del territorio pero prescindibles en la toma de decisiones políticas. Sin embargo, como decíamos, es el despliegue de una experiencia nacional-popular lo que permite constatar la posibilidad de un pasaje definitivo entre momentos históricos. En palabras del boliviano:

"frente al acoso, en el pasado, las clases nacionales no habían hecho sino resistir rechazando. Se identifican en la movilización militar y se reconocen como combatientes y se aperciben de que ser no es solamente resistir sino que también es necesario elegirse. Es el tránsito de la nación fáctica a la nación por sí misma, y del país resistente al país histórico, en un proceso por el cual, después de haber resistido a la negación de la nación, las clases que la contienen niegan la negación de la nación y tratan de realizar un Estado nacional, en sustitución de las semiformas estatales creadas por las clases extranjeras” (Zavaleta Mercado, 1967: 67).

Ahora bien, estas consideraciones generales acerca de la constitución efectiva de lo nacional ponían en primer plano las particularidades del pasaje histórico en las regiones semicoloniales. Es decir, cuáles eran los procesos sociales y políticos a través de los cuales se producía el tránsito de la facticidad a la mismidad, de la resistencia a la historia, en aquellos espacios que no estaban destinados "naturalmente" a constituirse en naciones. A diferencia de los estados europeos, que se convierten en naciones modernas a la par del despliegue del capitalismo, en las semicolonias dicha conversión se encuentra bloqueada por la propia configuración del sistema imperialista. Es decir que no se trata de un déficit de desarrollo de las regiones postergadas, sino que precisamente la última fase de constitución de los estados nacionales centrales obstaculiza de manera necesaria la realización de lo nacional en las semicolonias. El hecho de que la conversión de las semicolonias en estados nacionales perjudicara el normal funcionamiento del imperialismo le otorgaba una coloración particular a los planteos acerca de lo nacional en Bolivia. Por un lado, el nacionalismo no podía ser considerado sin la variable de la movilización de las masas. Dado el bloqueo impuesto a los estados semicoloniales, lo nacional en estas regiones se podía realizar aprovechando coyunturas desfavorables en el centro, tales como guerras o crisis, o bien "movilizando revolucionariamente a sus masas, haciendo la revolución” (Zavaleta Mercado, 1967, p. 78). A través de esta movilización, las clases nacionales interrumpen la inercia reproductiva del capitalismo y proceden a la realización del estado nacional. Por otro lado, el nacionalismo queda ligado de manera indisociable a la lucha de clases. En tanto el imperialismo sólo es posible a través del accionar de las oligarquías locales, la realización de lo nacional en las semicolonias implica necesariamente un enfrentamiento de clase. Para constituir el estado nacional, las clases nacionales deben luchar contra los sectores que históricamente han conspirado contra tal propósito. Razón por la cual el nacionalismo, "sin el concepto de lucha de clases no sería sino otra forma de alienación" (Zavaleta Mercado, 1967: 79).

Constituye un ejercicio relevante continuar indagando en el análisis de las contraposiciones operadas por Zavaleta Mercado entre las concepciones políticas del nacionalismo revolucionario y las que sustentaban el accionar de formaciones de la izquierda contemporánea. A diferencia del Zavaleta Mercado de la década de 1950, que contraponía la experiencia concreta del MNR a la militancia trotskista, el de fines de la década de 1960 opondrá la referencia de la Revolución Nacional al accionar de las formaciones de la llamada nueva izquierda latinoamericana. En este sentido, sus reflexiones sobre la campaña guerrillera del Che en Bolivia nos permiten constatar los dos elementos que operan en el contraste entre izquierdas y nacionalismo revolucionario. Por un lado, el mencionado relevo. Si en el caso de la oposición trotskista se trataba de evidenciar la esterilidad de una militancia disociada del lugar ocupado por Bolivia en el sistema capitalista, en el caso del guevarismo consistirá en un esfuerzo por dar cuenta de las razones del fracaso del accionar político en un contexto dictatorial. Por el otro, la prioridad otorgada a la relación entre historia y política. Es evidente que más allá de este desplazamiento de los objetos de reflexión, subsiste en Zavaleta Mercado una obsesión por los problemas relativos al modo en que las prácticas políticas de la izquierda contemporánea se conjugan con las historicidades en las que se despliegan. 
Al igual que en la lectura del accionar del POR importaba menos su filiación trotskista que sus intervenciones concretas, en su aproximación al guevarismo tenía menos relevancia la teoría del foco que las acciones cotidianas de las organizaciones guerrilleras. En este sentido, el texto que el boliviano le dedicó al balance de la experiencia guevarista, "El Che en el Churo", atendía "no el análisis de la teoría de la guerrilla, que tiene tantísimo especialista, y ni siquiera de la teoría que sirvió o fue utilizada por esta guerrilla, sino el caso concreto en su más exterior expresión, la práctica tal como fue el movimiento armado de Cordillera, Vallegrande y Chuquisaca” (Zavaleta Mercado, 1969: 16).

La campaña guevarista se prestaba quizás como ninguna otra práctica política de la nueva izquierda latinoamericana para un contrapunto con la experiencia de la Revolución Nacional. Dicho privilegio se originaba en el hecho de que el guevarismo había llevado a cabo su accionar en las mismas regiones en las que el MNR había desplegado la sublevación previa a la toma del poder. La diferencia entre ambas experiencias radicaba en que mientras los militantes emenerristas habían logrado concitar la adhesión del campesinado, los guerrilleros comandados por Guevara no habían recibido de ellos más que un apoyo circunstancial. La preeminencia que Zavaleta Mercado le otorgaba al problema de la práctica política hacía que en la evaluación del resultado de la experiencia guevarista quedaran explícitamente relegadas las explicaciones que remitían el fracaso de los guerrilleros a fenómenos externos tales como la eficacia del aparato represivo o las dificultades del territorio. Suspendidas estas respuestas habituales, la pregunta acerca de por qué las mismas regiones habían sido testigos de la movilización campesina en la década de 1940 y de la soledad del guevarismo en la de 1960, sólo podía ser contestada a partir de una indagación descarnada sobre lo que el boliviano denominaba "un vacío notorio, una desconexión flagrante, una falla en terreno" (Zavaleta Mercado, 1969: 16). Mientras el MNR aparecía a los ojos de los campesinos como los herederos de una historia de resistencia y rebelión, el guevarismo se presentaba como un elemento ajeno a las experiencias del pasado. Si el MNR fue "un partido que vivió, se expandió y se acorraló al servicio de la táctica”, el guevarismo nunca se preocupó por “decir a la gente por qué tenía que luchar junto a la guerrilla” (Zavaleta Mercado, 1969: 17). Mientras el MNR luchaba por las reivindicaciones campesinas a través de la negociación, el guevarismo sólo creía en una victoria total de los oprimidos. Si los militantes emenerristas actuaban sabiendo que la revolución es un proceso impuro y extenso, los guerrilleros consideraban a su misión la forma más elevada del ser humano. El desinterés que el guevarismo demostraba por la experiencia de los sujetos le impidió advertir que desde 1952 el campesinado se pensaba a sí mismo en términos de organización. Al igual que ocurría con aquella militancia trotskista de la década de 1950, la limitación fundamental del guevarismo había radicado en la liquidación de la historicidad. En los términos del boliviano:

“...en esas condiciones: ¿ ¿debía la pureza apoyarse en la impureza, el heroísmo en la transacción, el socialismo en la democracia burguesa? El mecanismo de la repulsión los lleva a desdeñar todo el pasado en su conjunto y allá donde buscaron campesinos en estado de desesperación espontánea, encontraron campesinos encuevados en una organización tan impura como real" (Zavaleta Mercado, 1969: 17)

III.

El lugar de la historia y política en la producción zavaletiana de la década de 1970 puede ser pensado a partir de un doble condicionamiento contextual. El primero de ellos remite a las ya mencionadas torsiones en el itinerario teórico del boliviano. Como hemos señalado, en aquellos años se produce en el seno de su pensamiento un movimiento que tiende a alejarlo de la tradición nacionalista y acercarlo a los esquemas interpretativos del marxismo. Al respecto, varios de sus comentaristas han destacado las implicaciones que dicho desplazamiento tuvo para una conceptualización renovada de la idea de nación. Así, Tapia (2002) se ha referido a un pasaje desde el reconocimiento de una nación fáctica hacia la comprensión de la nación en el marco de procesos económicos y sociales. Se habría producido en el Zavaleta Mercado de aquellos años un relevo de los problemas relativos a la afirmación efectiva de la nación por aquellos vinculados a la constitución de lo nacional en relación al desarrollo del capitalismo y la configuración de un sistema mundial. En esta misma línea Loyola (2006) ha cifrado el pasaje del boliviano en términos de una secularización de la idea de nación. La categoría de nación habría dejado de tener un carácter abstracto y homogeneizante para adquirir un sentido más historizado. El segundo elemento a tener en cuenta lo 
constituye el tipo de lectura sobre la Revolución de 1952 consolidado en aquellos años. Al respecto es sumamente interesante el recorrido propuesto por Tapia (2012) sobre lo que puede denominarse "los escritos del 52”, es decir las diferentes interpretaciones del acontecimiento revolucionario desarrolladas por la intelectualidad boliviana de la segunda mitad del siglo XX. En este sentido, el trabajo de Zavaleta Mercado en aquellos años estará enmarcado en una perspectiva sobre la Revolución Nacional diferenciada tanto de la de la década de 1950, la cual tenía un carácter testimonial, como la de la década de 1960, la cual estaba marcada por un afán crítico. En esta etapa, Zavaleta Mercado compartirá junto a otros investigadores bolivianos la tendencia a analizar la Revolución desde esquemas sociológicos e historiográficos.

Puede afirmarse que sus trabajos de comienzos de la década de 1970 constituyen aproximaciones a la Revolución Nacional mediadas fuertemente por el problema de la derrota política. Tanto La caída del MNR y la conjuración de noviembre, publicado en 1970, como Por qué cayó Bolivia en manos del fascismo, publicado en 1971, se ubican en un espacio de reflexión en el que fundamentalmente se pretendía encontrar las razones por las cuales la reacción había terminado imponiéndose frente a una política nacional y popular. En cambio, a medida que avancen los años, su lectura de la Revolución Nacional se volverá menos centrada en el golpe de 1964 inscribiéndose cada vez más en el doble condicionamiento contextual anteriormente señalado. En este sentido, “El proletariado minero en Bolivia” constituye un texto clave, en tanto allí se presenta una reflexión integral de lo que Zavaleta Mercado denomina “la matriz del 52”. Es posible remitir la particularidad de dicha reflexión a una reconstrucción de la historia política y social boliviana mediada principalmente por la singularidad del acontecimiento revolucionario. Es decir que los modos de conformación y despliegue de las clases, el Estado y los partidos eran analizados a partir de la singularidad histórica de la revolución de 1952. Ahora bien, un pensamiento en el que se cruzaban las dimensiones histórica y política empujaba la historización más allá de un devenir cronológico. El análisis de la realidad boliviana en términos de “la matriz de 1952” requería de una “estimación sintética o estructural del proceso” que sólo podía ser ofrecida por una operación de “aislamiento de coyunturas” (Zavaleta Mercado 1978: 522).

La recuperación de estas coyunturas históricas nos permite constatar que Zavaleta Mercado estaba interesado fundamentalmente en volver inteligibles los modos de articulación política entre el MNR y la clase obrera. La historización propuesta en "El proletariado minero en Bolivia” se detenía en aquellos momentos en los que se cristalizaban formas específicas de relación entre la experiencia de la clase obrera y la expresión política nacionalpopular. De esta manera, "la matriz del 52" se presentaba como una escena en dos actos. En primer lugar se imponía una clarificación acerca de las razones de la incorporación los trabajadores al MNR en la secuencia revolucionaria de la década de 1950. Esta vinculación se había originado en las denuncias realizadas por la militancia emenerrista de la masacre de Catavi. $\underline{6}$ La intervención de los parlamentarios y la prensa partidaria marcaron un quiebre en la experiencia política de los trabajadores mineros. Hasta la denuncia del MNR, el aislamiento de los obreros y la represión por ellos sufrida no había logrado repercusiones efectivas en el campo de la política nacional. Zavaleta Mercado ubicaba en este accionar del MNR el inicio de una vinculación estrecha entre el movimiento democrático y las reivindicaciones de clase obrera. En la secuencia revolucionaria que va desde mediados de la década de 1940 hasta la insurrección de 1952, la clase obrera boliviana actuará políticamente a través del MNR, al punto que resultará difícil una lectura escindida de la politicidad de ambos sujetos:

“desde el ciclo de huelgas de 1947 hasta la actuación armada de los mineros en Catavi y Potosí, en la guerra civil de 1949, el intento de insurrección en Villa Victoria, en La Paz, en 1950, y la propia insurrección de 1952, todo girará en torno de la clase obrera. Sin embargo, y a pesar de que los mineros aprobaron documentos tan independientes como la Tesis de Pulacayo, es notorio que consideraban al MNR como su partido, que lo que hacían lo efectuaban a través de él y que, en suma, aún no tenían intereses diferenciados con relación a la revolución democrática como conjunto” (Zavaleta Mercado, 1978: 525).

Sin embargo, en determinado momento el proceso revolucionario había adquirido un sentido tal que condujo a la 
reversión del mencionado proceso de articulación. En este sentido, la lectura histórica de Zavaleta Mercado se concentraba en el momento en el cual se había producido una bifurcación entre la politicidad del MNR y la de la clase obrera boliviana. Así, la aproximación a los itinerarios del MNR atendía sobre todo su giro conservador propiciado por la resistencia que las reformas democráticas generaban en determinados sectores de las masas. El desenvolvimiento del fenómeno revolucionario por una senda más conservadora que la de sus orígenes marcaba el fin de aquella primera coyuntura en la que el MNR se amoldaba políticamente a las masas y éstas contorneaban la politicidad emenerrista. Nos interesa al respecto indagar en la calibración que Zavaleta Mercado realizaba sobre los efectos de esta desvinculación política. Resulta significativo que el boliviano se refiriera a este fenómeno en términos de una "pérdida" o un "desgarramiento" (Zavaleta Mercado 1978, p. 554). El fracaso del MNR en la efectivización de una revolución democrática y su consecuente deriva conservadora habían dejado a la clase obrera sin un punto político de referencia. Y aquí se vuelve relevante la lectura de "la matriz del 52" en términos históricos. Se trataba de una verdadera pérdida o desgarramiento porque el MNR no constituía cualquier punto de referencia. A diferencia de otras instancias políticas sobre la que la clase obrera podía apoyarse, este punto de referencia se caracterizaba tanto por su "eficacia" como por su "extensión” (Zavaleta Mercado, 1978: 554). Es decir, constituía una plataforma desde la cual se podía incidir efectivamente en la política boliviana a la vez que habilitaba la posibilidad de alianzas con las otras clases dominadas. Era precisamente la pérdida de esta plataforma lo que había conducido a la clase obrera por el camino clasista de la Tesis de Colquiri y la Asamblea Popular. ${ }^{\underline{7}}$

Si nos atenemos a la evaluación que Zavaleta Mercado realizaba de esta coyuntura marcada por la desvinculación, podemos ver cómo resuena aquella reivindicación de la política como una economía de lo áspero y lo silencioso. Lejos de dotar de un carácter positivo a la escisión del MNR, Zavaleta Mercado constataba el alejamiento de la clase obrera de la única expresión política capaz de materializar sus reivindicaciones en políticas concretas. Leído desde una perspectiva en la que el abordaje de la política se cruza necesariamente con la dimensión de la historia, el MNR se presentaba como un partido no obrero pero como la única organización política capaz de vehiculizar las reivindicaciones obreras. En sus palabras:

“el MNR no fue jamás el partido de la clase obrera. La clase obrera militó en su seno casi en su totalidad, en determinado momento, pero eso no quería decir que fuera el partido de la clase obrera. No era un partido marxista-leninista ni era el partido de una clase, sino la alianza de varias clases bajo la hegemonía ideológica y práctica de la pequeña burguesía. Pero era el partido debajo del cual, y en cuyo nombre, se produjo el ingreso del proletariado a la política, su manifestación superestructural” (Zavaleta Mercado, 1978: 554).

Ubicado en esta secuencia, Lo nacional-popular en Bolivia se nos presenta como un libro singular pero no excepcional. Es decir, puede ser comprendido como el punto de llegada de un pensamiento marxista en torno a la relación entre historia y política en los marcos de la experiencia boliviana. Reflexión sistemática sobre la formación de lo nacional-popular en el país meridional, el texto póstumo de Zavaleta Mercado da cuenta de un esfuerzo por indagar en las relaciones entre las pautas de socialización y los proyectos de masa. Es decir, lo que a través de Max Weber era denominado la conexión entre la democratización social y la forma estatal. Ahora bien, la no excepcionalidad de Lo nacional-popular en Bolivia debe ser constatada a la par de las particularidades que el escrito presenta en tanto texto póstumo. Se ha señalado la singularidad de un libro en el que se propone tomar a la Revolución de 1952 como “centro del análisis” pero en el que dicho objetivo no es concretizado. Es sabido que la muerte de Zavaleta Mercado en 1984 le otorgó un carácter inacabado a las reflexiones cifradas en Lo nacionalpopular en Bolivia. Como ha destacado Tapia (2002: 335-336), el sentido de este trabajo era el de llevar a cabo un estudio de la historia moderna de Bolivia enfocado fundamentalmente en el período que se abría en 1952 y se cerraba en aquel presente de la década de 1980. Al no llegar a escribir el núcleo de su investigación, el libro fue generalmente procesado por sus lectores como un análisis de la guerra del Pacífico, la revolución federal de fines del siglo XIX y la guerra del Chaco. Resulta significativa la mención de Tapia a un esquema del capítulo sobre la Revolución Nacional que llevaba como título "La canción de María Barzola”. Como afirma su comentarista, el 
hecho de que Zavaleta Mercado eligiera el nombre de la heroína de la masacre de Catavi para su estudio sobre el proceso revolucionario hace suponer que el acontecimiento de 1952 era captado por el boliviano en una secuencia política que se remontaba hacia comienzos de la década de 1940.

Al igual que sugiere Giller en el artículo que forma parte de este dossier, creemos que una lectura de estas particularidades de Lo nacional-popular en Bolivia en términos de falta o incompletitud constituiría un acto de injusticia para con un trabajo tan potente como complejo. En nuestro caso, el interés en indagar los sentidos que adquiere la experiencia nacional-popular más allá de su ausencia puede ser remitido a dos problemáticas históricas y políticas. La primera de ellas consiste en la actualización del abordaje de la historia boliviana que precede al acontecimiento de 1952. Al respecto, vimos anteriormente cómo Zavaleta Mercado integraba todo lo ocurrido en el período en una matriz antinacional. Mientras la inserción de Bolivia en el sistema capitalista mundial y las clases dominantes del país conspiraban contra la nación, lo nacional anidaba perseverante entre la clase obrera y el campesinado. También afirmamos que el desplazamiento desde un esquema nacionalista hacia uno marxista conlleva el relevo de una idea de nación como factum hacia su problematización en los marcos del sistema capitalista. Si bien todo esto puede verificarse en Lo nacional-popular en Bolivia, puede también constatarse una prolongación del tratamiento de este período en términos de exclusión de lo popular. Al reconstruir la presencia del darwinismo social entre los intelectuales y políticos bolivianos de fines del siglo XIX, Zavaleta Mercado evidenciaba la construcción de un ordenamiento social basado en la otredad del indio. En el mismo sentido en que advertía en la década de 1960 el carácter encerrado y antinacional de la rosca, pero incorporando el problema de lo indígena, el Zavaleta Mercado de estos años enfatizará el carácter estructural de la exclusión de lo popular en los marcos del Estado oligárquico. Se abría en este sentido una atención particularizada sobre el caso boliviano en relación al resto de los países latinoamericanos. Si en Argentina o Chile un ordenamiento social según el modelo europeo podía legitimar la construcción de la nación en un sentido determinado, en Bolivia la idea de una nación europea constituía "una falacia radical, una imposibilidad no verosímil” (Zavaleta Mercado, 1984: 193). $\stackrel{8}{ }$

La segunda problemática sobre la cual nos queremos detener es la de los modos en los cuales es presentada en el texto la Revolución Nacional. Una indagación que, dadas las particularidades anteriormente repasadas, puede ser llevada a cabo a partir de una aproximación al prólogo del libro y a través de la recolección de pistas desperdigadas a lo largo de sus tres capítulos. En primer lugar, cabe destacar que Lo nacional-popular en Bolivia prolongaba la comprensión de la Revolución Nacional en los mismos términos que aquella “matriz del 52" introducida en "El proletariado minero en Bolivia”. Si bien la idea de una matriz no aparecía en un sentido literal, el boliviano justificaba que la Revolución Nacional constituyera el centro del análisis en el hecho de que allí se constataba “un despliegue orgánico” (Zavaleta Mercado, 1984: 10). Es decir, el acontecimiento revolucionario era procesado como la manifestación repentina de elementos que habían permanecido latentes. De la misma manera, el desarrollo de la matriz societal configurada luego de esta manifestación era siempre remitida a las particularidades del acontecimiento fundante. Las clases sociales reproducen de tal manera las condiciones de actuación en aquel momento de ruptura que puede afirmarse que "la historia posterior de Bolivia no es sino el desenvolvimiento de las características de la crisis de 1952” (Zavaleta Mercado, 1984: 10). Por otro lado debe señalarse que esta continuidad de la idea de “matriz del 52” será complementada con la calibración de la Revolución Nacional como la inauguradora del segundo ciclo estatal boliviano del siglo XX. La recomposición operada entre las clases políticas en los marcos del despliegue del acontecimiento revolucionario tiene como efecto la configuración de un nuevo sistema estatal. La crisis de 1952 le pone fin al ciclo estatal establecido a partir de la guerra federal, aquel estructurado alrededor de la oligarquía y el campesinado indígena en el contexto de inserción de la economía boliviana al sistema capitalista mundial. En contraposición con este primer ciclo estatal, la Revolución Nacional propicia una estatalidad caracterizada por la ampliación de las bases sociales de consenso, la introducción de la controversia política entre las clases dominadas, una nueva concepción espacial del país, la difusión de la ideología nacionalista y la conformación de un nuevo aparato represivo.

Destaquemos finalmente la existencia en Lo nacional-popular en Bolivia de un conjunto de postulados teóricos y 
metodológicos que nos permiten advertir el fuerte peso de una lectura historizada de la política. En primer lugar, Zavaleta Mercado proponía una revisión de la Revolución Nacional en unos términos diferenciados de la interpretación dependentista. Según el boliviano, el énfasis en el carácter dependiente de las formaciones sociales latinoamericanas podía llegar a negar la potencia de las historias nacionales. Si la dependencia sólo genera dependencia, ¿qué lugar ocupa lo nacional como instancia posibilitadora de una ruptura con los marcos de sujeción? En este sentido, si bien su análisis daba cuenta de la importancia de la coerción de las condiciones externas, intentaba evidenciar que “el núcleo de 1952 demuestra un grado importante de autodeterminación

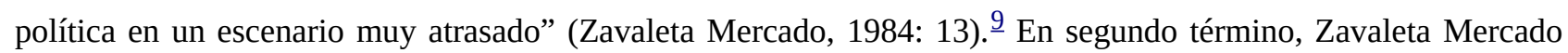
abonaba un posicionamiento marcadamente heterodoxo en relación a la comprensión de la politicidad de las clases sociales. Al respecto, su interpretación de la Revolución Nacional intentaba captar la experiencia del campesinado y los trabajadores más allá de las nociones clásicas acerca de la inevitabilidad del desarrollo histórico. En una declaración que puede ser puesta en sintonía con la historiografía marxista británica, el boliviano afirmaba que "no hay en Bolivia y es probable que en ninguna parte una correspondencia necesaria entre los indicadores del desarrollo económico-cultural y el grado de desarrollo político de los obreros” (Zavaleta Mercado, 1984: 14). De esta manera, por ejemplo, la idea del campesinado como clase receptora y el proletariado como clase donante era reemplazada por una aproximación a su experiencia guiada por el supuesto de que cada clase tiene su propia acumulación de clase y su propia historia dentro de la historia de las clases. $\underline{10}$

\section{IV.}

En un texto reciente dedicado a elucidar las particularidades del marxismo zavaletiano, Omar Acha (2016) postula a la obra del boliviano como una expresión teórica de la izquierda latinoamericana irreductible a apropiaciones estatal-populistas. Leída al calor del declive del llamado giro progresista de la política latinoamericana, esta afirmación tiende a colocar al pensamiento de Zavaleta Mercado en una relación de exterioridad con respecto a las experiencias políticas desarrolladas en la región en los últimos quince años. Resulta pertinente el señalamiento de que las formas de lo nacional-popular en la obra de Zavaleta Mercado difícilmente puedan ser trasladadas sin mediaciones a experiencias de tipo populistas. El énfasis en la potencia autodeterminativa de las masas que puede encontrarse en el último Zavaleta Mercado impide en gran medida tal operación. Ahora bien, como hemos visto a lo largo del texto, no menor es la discontinuidad operada en sus análisis entre la política nacional-popular y los posicionamientos de una izquierda desencontrada con las identidades políticas de los sectores populares. También es atinada la constatación de que en la obra zavaletiana se asienta una lectura problematizadora del Estado y la forma gobierno. La producción intelectual de Zavaleta Mercado no podría ser integrada en un espectro de pensamiento que tiende a reificar las formaciones estatales y gubernamentales de la política. Sin embargo, como también hemos visto, es igualmente perceptible en su obra la sospecha frente a las interpretaciones izquierdistas del Estado y la forma gobierno como meros garantes de la reproducción de las relaciones de producción. No por casualidad Zavaleta Mercado es una de las referencias a las que apelan Martín Cortés y Andrés Tzeiman (2017) en su reciente trabajo sobre las limitaciones de ciertos análisis marxistas para dar cuenta de la relación entre estatalidad y energía social en los marcos de la política latinoamericana contemporánea.

Discusiones como éstas dan cuenta de la potencialidad de la obra de Zavaleta Mercado para una comprensión de los procesos políticos desarrollados en la actualidad. Sus investigaciones minuciosas y sus agudas reflexiones constituyen insumos fundamentales para un pensamiento complejo sobre problemas tales como el Estado, las clases sociales y las particularidades de sus dinámicas históricas. En este sentido, nuestro recorrido se orientó a constatar la persistencia a lo largo de su trayectoria de una reflexión sobre lo nacional-popular. Intentamos demostrar que en la perseverancia de esta preocupación pueden encontrarse indicios de una concepción de la política en la cual la historicidad ocupa un rol relevante y de un compromiso teórico y político con la experiencia de la Revolución Nacional. De esta manera advertimos que los llamados momentos nacionalista y marxista de su itinerario le otorgaron una coloración diferenciada al tratamiento del acontecimiento revolucionario de 1952 y sus efectos históricos posteriores. En las décadas de 1950 y 1960, las reflexiones de Zavaleta Mercado estuvieron orientadas principalmente a la dilucidación de los requerimientos de una práctica política que permitiera 
trascender la potencia de lo antinacional. Atendiendo el problema de la constitución de la nación en las regiones semicoloniales, el boliviano tendió a la valorar el accionar del MRN como un sujeto político que inscribe su fuerza transformadora en una coyuntura atravesada por relaciones de fuerza. En las décadas de 1960 y 1970, sus objetivos se orientarán al procesamiento de la Revolución Nacional desde una perspectiva más analítica y reflexiva. Abordando esta experiencia en clave de "la matriz del 52", Zavaleta Mercado desarrolló un pensamiento sistemático acerca de las relaciones históricas entre el MNR y la clase obrera. En este marco, llevó a cabo un ejercicio historizador en el cual el declive de la experiencia nacional-popular era adjudicado al pasaje desde un momento de articulación entre ambos sujetos hacia uno en el cual dicha relación se presentaba como desgarrada.

\section{Notas}

1 El esfuerzo de Montenegro se presentaba como un episodio más de una tradición revisionista en la cual ocupaban un lugar destacado las obras de Isaac Tamayo, Ismael Vázquez y José Macedonio Urquidi. El nacionalismo revolucionario encontraba en estos ejercicios pretéritos antecedentes relevantes en la tarea de refutación de las tesis patologizantes e inferiorizantes sobre la historia nacional. Entre estas tesis, el afán refutativo del nacionalismo revolucionario apuntaba fundamentalmente, por su contundencia e influencia, a la del "pueblo enfermo" formulada por Alcides Arguedas (1909). En consonancia con la matriz historicista de la tradición nacionalista revolucionaria, la reconstrucción histórica ofrecida en Nacionalismo y coloniaje pretendía alcanzar un sentido "porvenirista”, es decir, no solamente “circunstancial” (Montenegro, 1944, p. 41). Para profundizar sobre el historicismo del nacionalismo revolucionario, ver Tapia (2009, pp. 15-16).

2 Zavaleta Mercado apuntaba al POR (Partido Obrero Revolucionario), organización trotskista boliviana que había sido fundada en 1935. Con una presencia destacada entre los campesinos y los obreros mineros, el POR había logrado en 1946 la aprobación por parte de la Federación Sindical de Trabajadores Mineros de Bolivia (FSTMB) de la célebre Tesis de Pulacayo, la cual estaba inspirada en la teoría de la revolución permanente de Trotsky y el Programa de Transición de la IV Internacional. Liderado por Guillermo Lora, el POR osciló entre una oposición frontal al programa nacional-popular del MNR y el apoyo a sus tendencias sindicalistas a través de la táctica del entrismo. Para una recorrido integral por la experiencia del POR, ver Sandor (2012).

$\underline{3}$ Resulta de interés destacar cómo el tratamiento de la llamada "política rosquera” prolongaba la caracterización del Estado pre-1952 como absolutamente antinacional y antipopular. En La formación de conciencia nacional, "la rosca" era definida como "un bolivianismo que sugiere la clandestinidad de un círculo de conjurados, el privilegio de un encierro calificado y antinacional” (Zavaleta Mercado, 1967: 68). Para una profundización de las características de la política oligárquica, ver Dunkerley (2003: 28-42).

4 Se conoce como Guerra del Chaco al conflicto bélico que enfrentó a Bolivia y Paraguay entre 1932 y 1935 por el control del Chaco boreal.

$\underline{5}$ De acuerdo a Loyola (2006), la conexión entre la idea de nación y la de clase social es indicativa de la búsqueda del boliviano por encontrar esquemas más productivos para dilucidar los problemas teóricos relativos a la lucha política, siendo precisamente esta búsqueda la que lo conducirá a un alejamiento de la tradición nacionalista y un apertura a la matriz teórica del marxismo.

$\underline{6}$ Se conoce como masacre de Catavi a la represión ejercida por el ejército boliviano en 1941 a una huelga de los trabajadores de las minas de estaño.

7 A través de la Tesis de Colquiri, formuladas en 1958, el movimiento obrero boliviano denunció la exclusión de los trabajadores de las decisiones políticas relativas a la minería propiciada por el gobierno de Víctor Paz Estenssoro. Asimismo postuló la necesidad de priorizar el sindicato frente al partido e hizo un llamamiento a la constitución de milicias obreras. Por su parte, la Asamblea Popular constituyó un esbozo de órgano de poder 
obrero y campesino que funcionó durante 1971.

$\underline{8}$ Los términos del planteo acerca de la exclusión estructural de lo popular, así como los años en los cuales este planteo tiene lugar, nos lleva a poner en sintonía el trabajo de Zavaleta Mercado con el de los autores inscriptos en la tradición subalternista hindú. Ver por ejemplo Guha (1982).

9 Para un análisis integral de la crítica zavaletiana a la teoría de la dependencia, ver Giller (2015).

10 En una declaración de principios que guarda estrecha relación con la del boliviano, E.P. Thompson (1989: 201) postulaba que "no deberíamos dar por sentada cualquier correspondencia automática, o demasiado directa, entre la dinámica del crecimiento económico y la dinámica de la vida social y cultural”. Para una lectura cruzada entre Zavaleta Mercado y Thompson, ver Acha (2016).

\section{Bibliografía}

Acha, O. (2016). “Clase y multitud en la obra tardía de René Zavaleta Mercado: interferencias thompsonianas”, en D. Giller y H. Ouviña (eds.). René Zavaleta Mercado. Pensamiento crítico y marxismo abigarrado, Buenos Aires, Instituto de Estudios de América Latina y el Caribe, pp. 171-187

Antezana, L. (1991). Dos conceptos en la obra de René Zavaleta Mercado: formación abigarrada y democracia como autodeterminación, College Park, University of Maryland.

Arguedas, A. (1909). Pueblo enfermo. Contribución a la psicología de los pueblos hispano-americanos, Barcelona, Vda. de Luis Tasso.

Dunkerley, J. (2003). Rebelión en las venas. La lucha política en Bolivia, 1952-1982, La Paz, Plural.

Cortés, M y Tzeiman, A. (2017). “Discutir el Estado. Dilemas estratégicos a la luz de los procesos políticos latinoamericanos”, en Theomai. Estudios críticos sobre sociedad y desarrollo, 35, pp. 202-219.

Gil, M. (2006). “Zavaleta Mercado. Ensayo de biografía intelectual”, en M. Aguiluz Ibarguren y N. de los Ríos Méndez (coords). René Zavaleta Mercado. Ensayos, testimonios y re-visiones, Buenos Aires, Miño y Dávila, pp. 93-109

Giller, D. (2015). "René Zavaleta Mercado frente a la "teoría de la dependencia”: algunas cuestiones en torno a la noción de la determinación dependiente y la forma primordial”, en Intersticios de la política y la cultura. Intervenciones latinoamericanas, 8, pp. 115-132

Giller, D. (2016). “El Mariátegui de Zavaleta. Entre Marx y el nacionalismo revolucionario”, en D. Giller y H. Ouviña (eds.). René Zavaleta Mercado. Pensamiento crítico y marxismo abigarrado, Buenos Aires, Instituto de Estudios de América Latina y el Caribe, pp. 119-145

Giller, D. y Ouviña, H. (2016). “René Zavaleta Mercado, un imprescindible”, en D. Giller y H. Ouviña (eds.). René Zavaleta Mercado. Pensamiento crítico y marxismo abigarrado, Buenos Aires, Instituto de Estudios de América Latina y el Caribe, pp. V-XI.

Guha, R. (1982). “On Some Aspects of the Historiography of Colonial India”, en R. Guha (ed.). Subaltern Studies. Vol. I. Writings on South Asian History and Society, New Delhi: Oxford University Press, pp. 1-8

Loyola, M. (2006). "René Zavaleta Mercado, pensar desde lo propio: el nacionalismo revolucionario”, en Aspectos. Revista del área de Estado, Economía y Gestión, 2, pp. 119-131. 
Montenegro, C. (1944). Nacionalismo y coloniaje. Su expresión histórica en la prensa de Bolivia, La Paz, Ediciones Autonomía.

Sandor, J. (2012). Bolivia's Radical Tradition. Permanent Revolution in the Andes, Tucson, University of Arizona Press.

Souza Crespo, M. (2011). “Apuntes sobre la obra de René Zavaleta Mercado, 1957-1974”, en R. Zavaleta Mercado. Obra Completa, Tomo I. Ensayos, 1957-1974, La Paz, Plural, pp. 11-28

Tapia, L. (2002). La producción del conocimiento local: historia y política en la obra de René Zavaleta, La Paz, La Muela del Diablo.

Tapia, L. (2009). “Prólogo”, en R. Zavaleta Mercado. La autodeterminación de las masas, Bogotá, Siglo del Hombre-CLACSO, pp. 9-29

Tapia, L. (2012). “Los escritos sobre el 52”, en Ciencia y Cultura, 29, pp. 9-17.

Tapia, L. (2016). “Consideraciones sobre el trabajo teórico de Zavaleta a partir de la obra de Marx”, en D. Giller y H. Ouviña (eds.). René Zavaleta Mercado. Pensamiento crítico y marxismo abigarrado, Buenos Aires, Instituto de Estudios de América Latina y el Caribe, pp. 11-28

Thompson, E.P. (1989). La formación de la clase obrera en Inglaterra, Barcelona, Crítica.

Zemelman, H. (1985). “Política y análisis en René Zavaleta Mercado”, en Estudios Sociológicos, 3 (9), pp. 561573.

Zavaleta Mercado, R. (1959). El asalto porista. El trotskysmo y el despotismo de las aclamaciones en los sindicatos mineros de Bolivia, La Paz.

Zavaleta Mercado, R. (1967). La formación de la conciencia nacional, Montevideo, Marcha.

Zavaleta Mercado, R. (1969). “El Che en El Churo”, en Marcha, pp. 16-18.

Zavaleta Mercado, R. (1971). Por qué cayó Bolivia en manos del fascismo, Santiago de Chile, Punto Final.

Zavaleta Mercado, R. (1995). La caída del MNR y la conjuración de noviembre (historia del golpe militar del 4 de noviembre de 1964 en Bolivia), Cochabamba, Los Amigos del Libro.

Zavaleta Mercado, R. (1978). “El proletariado minero en Bolivia”, en Revista Mexicana de Sociología, XL (XL), pp. 517-559.

Zavaleta Mercado, R. (1986). Lo nacional popular en Bolivia, México D.F., Siglo XXI. 